\title{
Three-year-olds understand belief: A reply to Perner
}

\author{
HENRY M. WELLMAN: \\ University of Michigan \\ KAREN BARTSCH \\ Pennsyivania State University
}

Wellman, H.M., and Bartsch, K., 1989. Three-year-olds understand belief: A reply to Perner. Cognition, 33: 321-326.

We contend that 3-year-olds understand belief within the context of an early belief-desire reasoning scheme (Wellman \& Bartsch, 1988). Perner (1989, this issue) claims that they do not, and offers three alternative interpretations of 3-year-olds' performances in our experiments.

In part, Perner seems to have misunderstood or overlooked several of our tasks and controls and thus failed to see the strengths of our results. This is clearest when he discusses his second alternative, that children interpret our stories as specify:ng where the target eally is and predict the character will look there. In his analysis of this alternative Perner (pp.316-317) focuses on only one of our story tasks, the Inferred Belief task. He says, quite rightly, that children could pass that task by simply misinterpreting the focal see-statement (e.g., Jane saw her markers on the shelf) as a clue to reality (e.g., the markers are really on the shelf). Then Perner admonishes us to in lude the "obvious control", that is, "asking children where the markers are" (p. 317).

This alternative interpretation is one that we ourselves considered, under the heading of reality assessment strategies (Wellman \& Baitsch, p. 264). And we explicitly controlled for such a strategy; our control includes and goes beyond that mentioned by Perner. We began by devising two sorts of tasks designed to defeat this strategy: Inferred Belief-control tasks and Discrepant Belief tasks. In these tasks target items really were in iicth possible locations. Hcre is an example Inferred Belief-control task:

There are magic markers in the desk and there are magic markers on the shelf. Jane saw magic markers on the shelf; not in the desk. Now Jane wants magic markeis. where will she look for markers? Aive there magir markers in the (other location) too?

If children understood that the markers are really in both locations even after they heard the see-statement (e.g., "Jane saw ..."), then they have not simply 
taken that statement as a clue to reality. Therefore to be sure that children did know that markers were in both locations, we asked exactly the sort of control question (italicized above) that Perner mentions. Three-year-olds were $88 \%$ correct on Inferred Belief-control tasks; to be correct they had to "predict the location appropriate to the character's belief ... [and] correctly assert that there were items in both locations" (Wellman \& Bartsch, p. 265). Three-year-olds were $82 \%$ correct on Discrepant Belief tasks and "all correct predictions were followed by correct answers on the control question designed to ensure that subjects knew the target objects were really in both locations" (p. 268).

Similarly, we explicitly considered a version of the associational strategy (Perner's first alternative interpretation) and included controls for its presence. This brings us to the heart of the matter with resnect to Perner's evaluation oi Weliman and Bartsch. Perner seems content to show that none of our conditions or tasks escape all three of his alternative interpretations. We admitted this sort of possibility in the original article, but contended that no alternative interpretation or response strategy could provide the observed pattern of performance across all our tasks and hence that the alternative to concluding that 3-year-olds understood belief was to endow them with "a concatenation of differing response strategies fortuitously appearing on just the right task version and not others" (Wellman \& Bartsch, p. 273). Perner claims that his objections escape this problem (footnote 6 and p. 319) because on every task at least two of his alternative strategies could provide the right answer. In fact, Perner's alternatives apply to our tasks as shown in Table 1. First, as that table shows (and as Perner seems to admit in footnote 7), it is not the case that all of our tasks are susceptible to at least two of his alternative interpretations (see Inferred Belief-control). More importantly, even where two of Perner's alternatives do apply, such as on Inferred Belief and Discrepant Belief tasks, it is not the same two strategies. Perner provides no rationale for how children might accomplish the needed shift between his alternative strategies, celectively annlying particular strategies to just the right tasks.

The problem of strategy selection is most evident in connection with Explicit False Belief tasks. Perner (p. 319) claims that on these tasks his alternativ. strategies "gave no clear direction" and for that reason 3-year-olds fail those tasks and those tasks alone. However, as noted in Table 1, Perner's alternative strategies $d o$ give a clear direction on false belief tasks, albeit one 3 -year-olds do not follow. Since these alternatives do apply, Perner must explain why 3-year-olds suppress them on Explicit False Belief tasks but not on the others. Perner's only attempt to do this is on p. 316, where he says that on an Explicit False Belief task "subjects don't have to rely on vague associ- 
Table 1. Application of Perner's three alternative interpretations to the tasks reported in Wellman and Bartsch (1988)

\begin{tabular}{llll}
\hline Tasks & $\begin{array}{l}\text { Associational } \\
\text { interpretation }\end{array}$ & $\begin{array}{l}\text { Reality } \\
\text { interpretation }\end{array}$ & $\begin{array}{l}\text { Thinking-of } \\
\text { interpretation }\end{array}$ \\
\hline Standard Belief & $\mathbf{Y}^{\mathrm{a}}$ & $\mathbf{Y}$ & $\mathbf{Y}$ \\
Not Belief & $\mathbf{Y}$ & $\mathbf{Y}$ & $\mathbf{Y}$ \\
Not-Own Belief & $\mathbf{Y}$ & $\mathbf{Y}$ & $\mathbf{Y}$ \\
Changed Belief & $\mathbf{Y}^{\mathrm{b}}$ & $\mathbf{Y}$ & $\mathbf{Y}$ \\
Inferred Belief & $\mathbf{Y}$ & $\mathbf{Y}$ & \\
Inferred Belief-control & $\mathbf{Y}$ & & \\
Discrepant Belief & $\mathbf{Y}$ & & $\mathrm{Y}$ \\
Explicit False Belief & $\mathbf{A}^{\mathrm{c}}$ & $\mathrm{A}$ & $\mathrm{A}$ \\
\hline
\end{tabular}

${ }^{a} \mathrm{~A}$ Y means that, yes, the alternatit e interpretation listed can account for children's responses on a task.

\footnotetext{
'In this task it is not ciea huw the asscriationai interpretation would apply. Because the character is ascribed two oppcsite beliefs, it might be expected that these two opnosing associations would yield random responding. To be conservative, however, we have credited the associational interpretation with a $\mathrm{Y}$ in this case.

'An A means that the interpretation would apply but its application does not account for children's responses. For example, as Perner admits (on p. 3), the belief statement (e.g., "Jane thinks her kitten is in the kitchen") in the Explicit False Belief task could create decisive associations; however, children's responses do not follow that pattern. Similariy, that belief state-nent could certainly be interpreted in a thinking-of manner, thereby creating a decisive preference, but that is not how children respond.
}

ations ... Iare, of course, will look for the kitten in the playroom since that's where the kitten is". Thus, Perner seems to say, as we discussed in our original article, that children will first attempt to determine where the target really is and resort to other strategies only if that attempt fails. But if children adopt such a reality-first approach, then they should do so not only on false belief tasks but on Discrepant Belief and Inferred Belief-control tasks as well. However, on those two types of tasks children do not predict the character will look where the targets really are (i.e., both locations equally) as would follow from a reality-first approach. Why not? Why do children opt for reality-first on some tasks (e.g., Explicit False Belief) but not others (e.g., Discrepant Belief)? Perner does not say, and for this reason it seems to us that his attempt to account for our data does constitute a concatenation of response strategies.

At this point, we wish to move beyond a defense of our original studies to consider more comprehensively whether 3-years-olds understand belicf. For Perner and for us the main goal is to properly characterize young children's 
understanding; a specific study is only a means to this end. Furthemore, in our original paper we explicitly outlined our approach: that no single study or condition will provide definitive results and hence that we seek an accurnulating set of findings. Ii should come as no surprise, therefore, that we have continued our research.

In Wellman and Bartsch (1988) we studied children's understanding of belief by presenting them with belief and desire information about a character and asking them to predict the appropriate action. In a recent series of studies (Bartsch \& Wellman, 1989) we reversed this procedure: we presented the child an action ("Jane is looking for her kitten under the piano") and asked the child to explain this ("Why do you think she is doing that?"). This method provides a further demonstration of children's understanding of belief. For example, it is possitle that young children solved some of our original prediction tasks by:

understanding only desires and preferences, not beliefs ... For example, perhaps when children heard "Fred thinks there are only magic markers in the desk, and no: on the shelf', they interpreted that statement to mean something like "Fred likes the desk and not the shelf", and so predicted accordingiy and correctly. (Bartsch \& Weliman, 1989, p. 948)

If 3-year-olds construe action only with respect to desires and interests, then their explanations of action should reflect this limitation. Such children would not be expected to spontaneously explain a character's action by invoking the beliefs or knowledge of the character; they would invoke only desires and preferences. Yiet in Bartsch and Wellman (1989) 3-year-olds provided just such belief explanations.

These explanations data are especially relevant to Perner's third alternative interpretation, his thinking-of interpretation. We wish to consicer this alternative interpretation further, because, although as currently formulated it cannot produce correct results across all our tasks (see Table 1), we agree with Perner that this is his most substantive and intriguing proposal. The upshot of this proposal (see also Perner, in press) is that when children hear statements such as "Sam thinks his dog is in the garage," they understand this to mean something like "Sam is thinking of the garage" or even "Sam thinks well of the garage." That is, such thinking-of translations "carry the implication of interest or even outright preference" for one of the alternatives (Perner, p. 317); "3-year-olds can cope with attributing to people interesting or desirable possibilities ('thinking of') but not misrepresentation ('thinking that')" (Perner, p. 318).

Independently of̂ Perner's analysis we have been pursuing a similar possibility. Bartsch and Wellman (1989) provided an indirect test of this sort 
of possibility and more recently we have devised a direct test (Wellman, in press, Chapter 3 ).

According to the thinking-of proposal, belief statements (e.g., "Sam thinks his dog is in the garage") function to describe the character as thinking of one of the two locations, and thus specify that location as the one in which the character is interested. In contrast, our proposal - the belief proposal is that young children often, if not always, understand such statements as specifying a belief. That is, belief statements provide the child with information about the character's specific conviction, for example, that Sam thinks the $d o g$ is in the garage. If the thinking-of proposal accounts for children's choices, then any belief statement about the correct alternative, even one specifying an irrelevant belief, creates the needed thinking-of preference. An irrelevant belief will do, because according to this proposal the child is not interpreting the belief statement as specifying a belief, but simply as stating that the character is interested in one of the alternatives. If the belief proposal is true, however, and children understand belief, then some belief statements will be relevant to the character's actions buit some wili not. For example, if the character thinks that the specified location contains the target item, this belief is relevant to his desire and thus, via belief-desire reasoning, to the character's action. If, however, the character thinks (irrelevantly) that the lucationi is blue or green, although he is thinking of that location, this belief is not relevant to the character's desire to find the object and thus should not constrain the character's search actions.

Therefore, we tested 3-year-olds on two tasks: Irrelevant Belief tasks and Relevant Belief tasks (Wellman, in press, Chapter 3). To make a long story short, the data firmly supported the belief proposal. Three-year-olds did not simply mistransiat $\in$ belief statements as statements of interest. They appropriately understood them as belief statements rather than thinking-of statements and hence appropriately distinguished between relevant and irrelevant belief tasks.

\section{Conerlusion}

The studies reported in Wellman and Bartsch (1988) were intended as a convincing but initial demonstration of 3-year-olds' understanding of belief. Those data are substantiaily less subject to alternative interpretations than Perner claims, buc addressing the substantive issues requires an accumulating series of research. As the studies accumulate, nowever, we are increasingly convinced thit 3-year-olus understand that people have beliefs and reason about person's actions with respect to those beliefs. Of course, they do not 
always do so nor is their reasoning always appropriate. We wish to emphasize that we are indebted to Perner, because in his written work and in our informal discussions together he poses creative alternatives that aid us in addressing the important questions in an increasingly comprehensive fashion.

\section{References}

Bartsch, K.. \& Wellman, H.M. (1989). Young children's attribution of action to beliefs and desires. Child Development. 60, 946-964.

Pirner, J. (1989). Is "thinking" belief? Reply to Wellman and Barts?h Cognition, 33, 315-320. this issue.

Perner, $\mathbf{J}$. (in press). On representing that: The asymmetry betwe $n$ helief and desire in children's theory of rnind. In C. Moore \& D. Frye (Eds.), Children's theories of mind. Hillsdale, NJ: Erlbaum.

Wellman, H.M. (in press). The child's theory of mind. Cambridge, M..: MIT Piessíbradiord Books.

Wellmân, H.ivi., \& Bartsch, K. (1988). Young children's reasoning about beliefs. Cognition, 30, $239-277$. 